\title{
Article
}

\section{Choosing the place of death: Empowering motor neurone disease/amyotrophic lateral sclerosis patients in end-of-life care decision making}

Chhetri, Suresh Kumar, Bradley, Belinda Fay, Callagher, Pauline, Addison-Jones, Robert, Bennett, Wendy, Gardham, Joyce, Parkes, Amy, Lea, Robert William and Majeed, Tahir

Available at http://clok.uclan.ac.uk/19892/

Chhetri, Suresh Kumar, Bradley, Belinda Fay ORCID: 0000-0002-3426-8924, Callagher, Pauline, Addison-Jones, Robert, Bennett, Wendy, Gardham, Joyce, Parkes, Amy, Lea, Robert William and Majeed, Tahir (2015) Choosing the place of death: Empowering motor neurone disease/amyotrophic lateral sclerosis patients in end-of-life care decision making. Palliative Medicine, 29 (7). pp. 667-668. ISSN 0269-2163

It is advisable to refer to the publisher's version if you intend to cite from the work. http://dx.doi.org/10.1177/0269216315570412

For more information about UCLan's research in this area go to http://www.uclan.ac.uk/researchgroups/ and search for <name of research Group>.

For information about Research generally at UCLan please go to http://www.uclan.ac.uk/research/

All outputs in CLoK are protected by Intellectual Property Rights law, including Copyright law. Copyright, IPR and Moral Rights for the works on this site are retained by the individual authors and/or other copyright owners. Terms and conditions for use of this material are defined in the policies page. 


\title{
Choosing the place of death: Empowering motor neurone disease/ amyotrophic lateral sclerosis patients in end-of-life care decision making
}

Palliative Medicine

20I5, Vol. 29(7) 667-668

(C) The Author(s) 2015

Reprints and permissions:

sagepub.co.uk/journalsPermissions.nav DOI: $10.1177 / 0269216315570412$

pmi.sagepub.com

@SAGE

\author{
Suresh Kumar Chhetri',2, Belinda Fay Bradley², \\ Pauline Callagher', Robert Addison-Jones', Wendy Bennett', \\ Joyce Gardham', Amy Parkes', Robert William Lea ${ }^{2}$ \\ and Tahir Majeed'
}

Motor neurone disease/amyotrophic lateral sclerosis $(\mathrm{MND} / \mathrm{ALS})$ is a fatal neurodegenerative disease that requires special attention at the end-of-life, particularly because disability is relentlessly progressive and death generally occurs in a predictable fashion. ${ }^{1,2}$ In the absence of a cure, palliative care and advance care planning (ACP) are key management strategies. ${ }^{1,2}$ The quality of care provided throughout the illness profoundly influences the end-of-life care (EOLC). ${ }^{1-3}$ The 'End of Life Care Strategy' aims at promoting excellence in EOLC. ${ }^{3}$ The central aspect of this strategy concerns patients' preference for place of death. There is little in the literature about enabling MND/ ALS patients to make choices about their EOLC, particularly relating to the preferred place of death (PPD).

Honouring patient's choice for PPD is important, and this can be achieved through ACP. ${ }^{2,3}$ The Preferred Priorities for Care (PPC) document is a patient-held dynamic record that can be used as an ACP tool to promote discussion and documentation of wishes, preferences and priorities for care in relation to end-of-life issues. ${ }^{3,4}$ The Preston MND care and research centre serving a population of 1.6 million in North West England offers PPC document to all MND/ALS patients.

We reviewed the case notes of patients who died in 2012 and 2013 to investigate whether completion of PPC document affected actual place of death or hospital use towards end-of-life. There were a total of 99 deaths, of which 33 (33.3\%) occurred in hospital. PPC document was completed by 52 patients $(52.5 \%) ; 29$ (55.8\%) identified home as a PPD and the rest identified hospice/home $(n=11 ; 21.2 \%)$, hospice $(n=10 ; 19.2 \%)$ or nursing home $(n=2 ; 3.8 \%)$. None identified hospital as a PPD. The majority of patients completing the document (completers) died at home $(n=18 ; 34.6 \%)$ or hospice $(n=16$; $30.8 \%) ; 12(23.1 \%)$ died in hospital and $6(11.5 \%)$ died at nursing home. PPC document was not completed in 47 cases $(47.4 \%)$. Majority of those who did not complete (non-completers) the document died in hospital $(n=21$; $44.7 \%)$, while $16(34 \%)$ died at home, $6(12.8 \%)$ at nursing home, $3(6.4 \%)$ at hospice and $1(2.1 \%)$ while on holiday (Figure 1). A chi-squared test demonstrates statistically significant difference between whether patients completed the document and where they died $\left(\chi^{2}(16)=71.06\right.$, $p<0.001)$. Odds ratios indicate that non-completers were 1.96 times more likely to die in hospital. In contrast, completers were 4.84 times more likely to die in a hospice.

The main reason for admission in both groups was respiratory failure/shortness of breath (12 non-completers; 6 completers); 4 non-completers and none of the completers were admitted with general deterioration. Other causes for admission included falls, breakdown of care and other medical reasons. The major reason for non-completion of PPC document was reluctance or refusal by the patient to discuss EOLC issues (51\%). Other reasons included late diagnosis, inability to make wishes known due to cognitive impairment and unexpected deterioration.

Majority of people would prefer to die at home, but unfortunately, this is not the reality they experience. ${ }^{3}$ Healthcare towards end-of-life places a major resource burden on the health service. ${ }^{3,5}$ A retrospective study of 1600 hospitalisations in patients with MND/ALS demonstrated prolonged and expensive admissions, a high in hospital mortality rate and few routine discharges. ${ }^{5}$ Most of our patients who completed the PPC document were

\footnotetext{
'Preston MND Care and Research Centre, Department of Neurology, Royal Preston Hospital, Lancashire Teaching Hospitals NHS

Foundation Trust, Preston, UK

2University of Central Lancashire, Preston, UK

\section{Corresponding author:}

Suresh Kumar Chhetri, Preston MND Care and Research Centre, Department of Neurology, Royal Preston Hospital, Lancashire Teaching Hospitals NHS Foundation Trust, Preston PR2 9HT, UK.

Email: chhetri@doctors.org.uk
} 


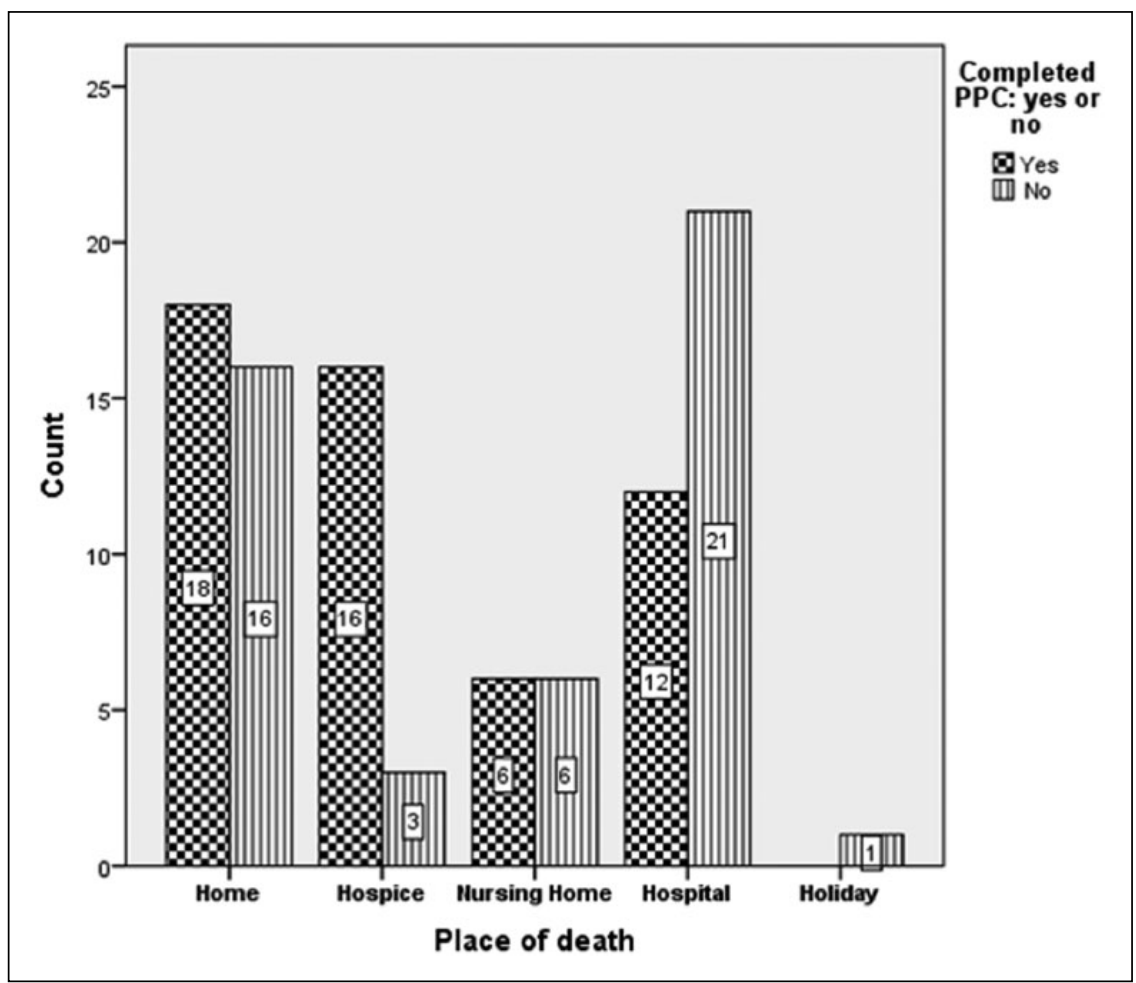

Figure I. Actual place of death of patients who completed the PPC document $(n=52)$ as compared to those that did not ( $n=47)$.

able to achieve their PPD. Completion of document was associated with significantly reduced hospital deaths and increased hospice deaths: $44.7 \%$ of non-completers died in hospital. This value is strikingly similar to MND/ALS deaths in hospitals (45.1\%) in England. ${ }^{6}$ A significant proportion of these patients could potentially be cared at home, if their care preferences are known. The PPC document thus facilitates multi-agency collaborative working including involvement of specialist palliative care team and enables MND/ALS patients to die in their PPD. ACP has also been shown to yield positive experiences in caregivers of patients with MND/ALS and reduce grief related symptoms in the bereavement phase. ${ }^{2}$ Patients/ relatives feel empowered by participating in decisions about EOLC, and shared decision making is valued at the end-of-life. ${ }^{1-3}$

We demonstrate that the use of PPC document empowers patients to gain control over their EOLC when dealing with an uncontrollable cruel illness, enables delivery of personalised care and reduces hospital admissions. EOLC should be discussed early and throughout the disease trajectory as an integral part of holistic care in MND/ALS. The PPC document is commonly used in the field of oncology but not in MND/ALS. Our study supports the view that PPC document should also be offered to MND/ALS patients as a standard of care.

\section{Declaration of conflicting interests}

The authors declare that there is no conflict of interest.

\section{Ethics}

The study was approved by the clinical governance and audit department, Lancashire Teaching Hospitals NHS Foundation Trust.

\section{Funding}

Dr Chhetri has received educational grant from the George Barton Motor Neurone Disease trust.

\section{References}

1. Mitsumoto H, Bromberg M, Johnston W, et al. Promoting excellence in end-of-life care in ALS. Amyotroph Lateral Scler Other Motor Neuron Disord 2005; 6: 145-154.

2. Ray RA, Brown J and Street AF. Dying with motor neurone disease, what can we learn from family caregivers? Health Expect 2014; 17: 466-476.

3. Department of Health. End of Life Care Strategy: promoting high quality care for all adults at the end of life, https:// www.gov.uk/government/publications/end-of-life-carestrategy-promoting-high-quality-care-for-adults-at-the-endof-their-life (2008, accessed 15 September 2014).

4. Storey L. Introduction to the preferred place (priorities) of care tool. End Life J 2007; 1: 68-73.

5. Lechtzin N, Wiener CM, Clawson L, et al. Hospitalization in amyotrophic lateral sclerosis: causes, costs, and outcomes. Neurology 2001; 56: 753-757.

6. Sleeman KE, Ho YK, Verne J, et al. Place of death, and its relation with underlying cause of death, in Parkinson's disease, motor neurone disease, and multiple sclerosis: a population-based study. Palliat Med 2013; 27: 840-846. 